\title{
Migración y movilidad de los trabajadores cualificados extranjeros de las empresas en México ${ }^{1}$
}

\section{Migration and mobility of companies' foreign skilled workers in Mexico}

\author{
Cristóbal Mendoza \\ Departamento de Sociología \\ Universidad Autónoma Metropolitana-Iztapalapa, Ciudad de México, México \\ ORCID: http://orcid.org/oooo-00oI-8694-6830 \\ DoI: http://dx.doi.org/10.28928/revistaiztapalapa/842018/atc1/mendozaperezc
}

\begin{abstract}
Resumen
La literatura sobre migración y movilidad del personal cualificado de las empresas se ha centrado básicamente en el estudio del colectivo de expatriados. Esta pone el énfasis en los mercados internos de las transnacionales, en patrones de migración temporal y en trayectorias laborales ascendentes. A partir de 129 entrevistas semiestructuradas con inmigrantes españoles e italianos, este artículo discute los postulados de la literatura y, para ello, analiza y compara la inserción laboral de expatriados y otros trabajadores cualificados de las empresas en México. Primero, el artículo discute el papel de México como destino permanente, en un contexto de globalización y crisis económica. Posteriormente, se aborda el papel del Estado mexicano y los recientes cambios en su política migratoria, a la hora de entender los flujos migratorios cualificados. Finalmente, se expone la variedad de condiciones laborales y contractuales de este colectivo, que apuntan a una lectura compleja de la inserción laboral de los profesionales inmigrantes en México. Palabras clave: migración cualificada, movilidad, transnacionales, México, migración laboral
\end{abstract}

\begin{abstract}
Literature on migration and mobility of companies' skilled workers has mainly focused on expatriates. This literature puts the emphasis on labour markets of transnational corporations, temporary migration, and upward labour trajectories. From 129 semi-structured interviews with Italian and Spanish immigrants, the article discusses the main patterns accounted on literature, by comparing and analyzing labour incorporation of expatriated and other skilled workers of companies in Mexico. First, the article discusses the role of Mexico as a permanent destination, in a context of globalization and economic crisis. Posteriorly, it revolves around the role of the Mexican state and the recent changes in its migration policy in order to understand current migration flows. Finally, the article exposes the variety of working and hiring conditions of this group, suggesting a more complex view on labour incorporation of immigrant professionals in Mexico.

Keywords skilled migration, mobility, transnational corporations, Mexico, labour migration.
\end{abstract}

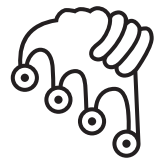

IZTAPALAPA

Agua sobre lajas

*cmp@xanum.uam.mx 
$L$ a literatura sobre migración cualificada ${ }^{2}$ es minoritaria en el conjunto de estudios de migración, quizá porque, al tratarse de un grupo relativamente poco numeroso, constituye un colectivo social y estadísticamente "invisible" (Salt, 1992; Peixoto, 200I). Sin embargo, tiene un gran impacto en las economías, los mercados de trabajo y las sociedades de los países de destino (Appleyard, 1995; Hall y Appleyard, 20II). Esta literatura tiene un sesgo eminentemente laboral, resaltando los trabajos centrados en la "fuga de cerebros" (véase, por ejemplo, Smith y Favell, 2006; Bhagwati y Hanson, 2009; Chiswick, 20II, para algunos estudios recientes) y aquellos que analizan la movilidad de los trabajadores expatriados dentro de las empresas transnacionales (véase, por ejemplo, Salt, 1992, Millar y Salt, 2008). Desde una perspectiva geográfica, estas investigaciones se han centrado mayormente en la incorporación laboral de los migrantes de alta cualificación en los países considerados como desarrollados y en los impactos negativos de esta emigración en los de expulsión, en su mayoría con menores niveles de desarrollo económico y social. Este artículo cambia el enfoque y estudia los movimientos migratorios desde dos países del sur de Europa (España e Italia) a uno considerado en vías de desarrollo

1 Este artículo se basa en el proyecto ¿Fuga o suma de cerebros?: Migración calificada del sur de Europa a las nuevas ciudades emergentes mexicanas (Proyecto CONACYT de desarrollo científico para atender problemas nacionales. Convocatoria PDCPN2OI3-OI, núm. 2I2208, octubre 20I4-septiembre 20I6).

2 La definición de "migrante cualificado" es motivo de polémica en la literatura. Algunos autores defienden que la "cualificación" se debe definir con respecto a la educación formal y otros argumentan que su aspecto decisivo es la incorporación laboral. Así, Meier (20I5), retomando esta última perspectiva, opina que muchos migrantes, considerados de alta cualificación por su nivel educativo, en realidad no consiguen obtener una posición profesional de acuerdo con su formación en los países de destino. En general, sin embargo, la literatura coincide en que un "migrante cualificado" es aquel que posee un diploma universitario (Eich-Krohm, 2013). Se asume también que las personas con estudios superiores pueden, en general, desarrollar tareas de mayor complejidad que el resto de trabajadores (Fratesi, 2014). 
(México). Cuando este ángulo geográfico de análisis se ha abordado en la literatura, el énfasis ha sido en migraciones temporales y desplazamientos cortos de expatriados (Willis y Yeoh, 2000; Beaverstock, 2002), pero no en migración permanente.

Entre los países considerados como desarrollados, los de Europa meridional se caracterizan por un fuerte desempleo estructural y grandes diferencias regionales, que se han visto agudizados por la crisis económica de 2008. En el caso de España, $42.9 \%$ de sus jóvenes, de entre 15 y 29 años, no tenían empleo a finales de 2016 (INE, 20I7). No sorprende, en este contexto, que el número de emigrantes procedentes del sur europeo haya aumentado de forma notable en la última década. Los datos oficiales apuntan en este sentido y señalan que, en el caso de los españoles, aquellos que viven permanentemente en el extranjero han pasado de I 47I 69I en enero de 2009 a 2305030 en enero de 2016 (INE, 2016), un aumento total de 833339 para todo el periodo y un incremento anual aproximado de 119000 personas. En términos relativos, el número de emigrantes ha aumentado $56.6 \%$ entre 2009 y 2016, lo cual constituye una tasa anual de crecimiento de $6.4 \%$. En el caso de los italianos, Dumont, Spielvogel y Widmaier (2010) calculan que los emigrantes constituyen $5.2 \%$ de la fuerza laboral total del país y 7.I \% de los titulados universitarios.

Las ciudades globales latinoamericanas, por su parte, son un destino importante para los migrantes procedentes del sur de Europa. En particular, México los atrae de forma creciente. Así, en 2009, los españoles constituían la segunda nacionalidad, por número de extranjeros en el país, después de los estadounidenses (Rodríguez Chávez y Cobo, 2012). Los datos de los consulados en México apuntan en la misma dirección: los españoles residentes en el país han pasado de 69 57I en 2009 a I23 I89 en 2016 (INE, 2016), un crecimiento absoluto de 53618 entre esos años, que constituye un relevante 77.I \% de aumento. De hecho, la tasa de crecimiento de estos inmigrantes en México es mayor que la tasa para el conjunto de españoles en el mundo ( $8.2 \%$ en el caso de México y $6.4 \%$ la tasa mundial). No obstante, los datos oficiales no reflejan de forma precisa esta tendencia ascendente, dado que muchos inmigrantes optan por no registrarse en sus consulados en el país de destino. Aunque estos datos no se encuentran desagregados por actividad económica ni profesión, los estudios de corte cualitativo apuntan que una parte relevante de la población activa extranjera en México está compuesta por inmigrantes de alta cualificación (Mendoza y Ortiz-Guitart, 2006; Palma Mora, 2006).

Este artículo, a partir de la discusión teórica sobre la migración y movilidad de las personas cualificadas que se detalla en el próximo apartado, analiza la inserción laboral de los colectivos de alta cualificación, de nacionalidad española o italiana, en México. En particular, se analizan los patrones de movilidad y migración de 
los profesionales extranjeros de las empresas, y se contrapone la inserción laboral del personal de gestión y técnico que ha llegado a México a través de los mercados internos de las transnacionales ("expatriados") con la de aquellos que arribaron de forma "independiente", al margen de estas corporaciones globales. De esta forma, se analizan diferentes aspectos de la inserción y la movilidad laborales de estos profesionales en México y, a partir de estas experiencias, se contrastan, y en algunos casos rebaten, algunos aspectos dominantes en los paradigmas de interpretación que dominan en los estudios de migración cualificada.

En concreto, se revisan cuatro aspectos que la literatura científica ha soslayado a la hora de abordar el análisis de los flujos migratorios de estos trabajadores de alta cualificación. La discusión parte del papel de México como destino permanente de estos profesionales, en un contexto de globalización de la economía mundial y de crisis económica. En este apartado se apunta que gran parte de los entrevistados pueden desarrollar sus carreras en México, de tal forma que algunos expatriados deciden permanecer en el país. Posteriormente, se aborda el papel del Estado mexicano a la hora de entender los flujos migratorios cualificados. Este aspecto es de interés porque generalmente se obvian las políticas migratorias en el caso de los países con menos niveles de desarrollo, suponiendo que estos no ponen trabas a la libre entrada de dichos profesionales. En el caso de México, el cambio de ley migratoria en 2012 y la llegada de personas jóvenes huidas de la crisis económica han comportado la existencia de inmigrantes de alta cualificación irregulares, sin papeles, trabajando en el país. En la misma línea, el artículo analiza las diferentes condiciones laborales que tienen los que han llegado bajo el paraguas de los mercados internos de las transnacionales y el resto. Se exponen, de esta manera, una variedad de situaciones y condiciones laborales que apuntan hacia una lectura mucho más compleja que la visión apuntada por la literatura. Finalmente, se aborda un aspecto poco explorado, relativo a los conflictos en el lugar de trabajo, derivados de culturas empresariales o laborales diferentes. Este aspecto, aparentemente menor, es de gran importancia para algunos expatriados que manifiestan su deseo de regresar a España, al no poder adaptarse al medio laboral local.

\section{Migración cualificada: "fuga de cerebros" y movilidad dentro de las transnacionales}

La "fuga de cerebros" fue el enfoque inicial a partir del cual se analizó la migración de personas cualificadas. Los primeros estudios de los años setenta, fuertemente 
influenciados por las teorías de inspiración marxista, hacían énfasis en aspectos relativos al subdesarrollo y la dependencia, asociados al desplazamiento (por ejemplo, Bhagwati y Hamada, 1974; Portes, 1976). Posteriormente, sin embargo, se plantea reemplazar el concepto de "fuga de cerebros" por el de circulación o intercambio de cerebros (brain gain), que refleja un mayor grado de movilidad entre países y la mejora del capital humano que puede significar este tipo de migración tanto en los países de origen como de destino (Docquier y Rapoport 2orI; Giannetti, Liao y Yu, 20I2). Los conceptos de circulación o intercambio de cerebros reflejarían mejor el momento actual de globalización y un mayor nivel de movilidad de las personas de alta cualificación (Angel-Urdinola, Takeno y Wodon, 2008; Solimano, 2008). Estos conceptos implicarían no solo un mayor número de desplazamientos, sino flujos multidireccionales en un mundo cada vez más integrado (Docquier y Rapoport, 20II; Giannetti, Liao y Yu 20I2), lo cual podría suponer, incluso, para algunos profesionales, que la movilidad y la circulación son consustanciales a sus vidas, pudiendo incorporar diferentes lugares en circuitos o espacios de movilidad (Ong, 1999; Pellegrino, 200I).

El segundo enfoque dominante en los trabajos sobre migración cualificada es el relativo a la movilidad y migración dentro de las empresas transnacionales. Los primeros estudios, en los años ochenta, interpretaban el fenómeno a partir de un esquema centro-periferia, donde las transnacionales, en un contexto de internacionalización, expandían sus actividades hacia países en vías de desarrollo. Los desplazamientos del personal cualificado se producían dentro de los mercados internos de estas compañías ("expatriados"), desde las sedes centrales, ubicados en países desarrollados, a las filiales, en regiones con menor grado de bienestar (por ejemplo, Findlay, 1989; Beaverstock, I99I). De acuerdo con esta línea de análisis, que tiene una fuerte influencia de la teoría del sistema mundo, la mano de obra cualificada sería una continuación de los movimientos de capitales hacia los países de industrialización reciente, a diferencia del resto de trabajadores que se orientaría en dirección contraria al capital. El personal de las sedes centrales sería el encargado de supervisar y coordinar tareas altamente especializadas en los países con menores niveles de desarrollo (véase, por ejemplo, Mendoza, 1994, para un estudio de los técnicos y profesionales de las empresas alemanas en España a principios de los años noventa). Este esquema de interpretación estaba fuertemente influenciado por la Nueva División Internacional del Trabajo (para mayor información al respecto, véase Fröbel, Henricks y Kreye, 1980), y da por supuesto que los trabajadores de los países donde se ubicaba la filial de la transnacional carecían de una formación especializada. 
Siguiendo esta línea de análisis, la migración cualificada en el marco de las empresas transnacionales en México podría responder a un modelo centro-periferia. Estas, en un contexto de internacionalización, expanden sus actividades hacia países en vías de desarrollo. En particular, las españolas han experimentado un sustancial aumento desde los años noventa en tierras mexicanas (véase, por ejemplo, Noceda, 2005; Relea, 2005; Mendoza y Ortiz-Guitart, 2006), donde podrían preferir reubicar temporalmente personal directivo, de gestión o técnico como parte de sus planes de expansión. Esta línea de argumentación, en cierta manera, se ha visto superado por el proceso de globalización actual, que impone explicaciones más complejas en un mundo más interconectado. México, en este sentido, se ha caracterizado por políticas de apertura económica que, acompañadas por una relativa estabilidad política en el contexto iberoamericano, han hecho atractivo al país para la inversión extranjera.

En este sentido, la literatura, intentando superar esquemas rígidos de interpretación, ha abordado el fenómeno desde una perspectiva más compleja y ha analizado la articulación de trayectorias laborales de los trabajadores cualificados en intrincados mapas mundiales de sucursales, filiales y casas matrices (Koser y Salt, 1997) que se relacionan con diferentes puestos de responsabilidad y dirección, en principio dentro de una lógica de movilidad laboral ascendente (por ejemplo, Findlay et al., 1996; Iredale, 200I; Millar y Salt, 2008). De esta manera, se han podido visibilizar otros aspectos, como son patrones más flexibles de movilidad del personal cualificado (por ejemplo, viajes de negocios; Beaverstock et al., 2009) o el papel de los mercados laborales externos a las empresas, mediante procesos de subcontratación de servicios en los países de destino, de cara a disminuir los desplazamientos (Beaverstock, 1996).

Este último aspecto pone de relieve que la movilidad de los profesionales de las empresas se debe entender en un contexto más general, y no dentro de los límites estrictos de la política interna de las transnacionales. Estas corporaciones, mayormente de los sectores industrial y financiero, fueron el inicio del proceso de globalización, el cual incluye actualmente, con la firma de los grandes tratados comerciales, a todos los sectores de actividad, al margen de su tamaño. Por otro lado, la creciente transnacionalización de la economía en su conjunto implica no solo que la producción de bienes y servicios se homogeneice a nivel mundial, sino que también las trayectorias formativas de los trabajadores no sean fácilmente distinguibles por países (véase, por ejemplo Ackers, 2005). Es más, Khadria (2009) afirma que los flujos migratorios contemporáneos están mayormente dominados por la búsqueda de trabajadores en un mundo cada vez más global, a diferencia de la situación de hace treinta años, en que los flujos estaban dirigidos por el exceso de oferta de trabajadores (véase también Kuptsch y Pang, 2006). En este tenor, México se posiciona en la economía mundial como 
mercado emergente, que podría implicar la demanda de trabajadores profesionales en algunas ramas industriales o de servicios en expansión.

$\mathrm{Al}$ considerar las transnacionales como parte de un engranaje más general, podemos entender también que los profesionales de las transnacionales opten por trayectorias laborales más complejas, que contemplen entradas y salidas de estas corporaciones; empresas que, por otro lado, pueden ser muy demandantes en cuanto a su política de movilidad, dependiendo de planes de expansión y contracción cambiantes en función de la coyuntura económica. De hecho, los estudios recientes sobre migración cualificada, más que poner el énfasis en corporaciones específicas o en un tipo de empresa, han preferido centrarse en colectivos/nacionalidades concretos. A modo de ejemplo, podríamos destacar los estudios de Boyd (200I), en torno el grupo de los ingenieros asiáticos en Canadá; Pellegrino (200I) y Lozano y Gandini (20II), centrados en las tendencias de la migración cualificada latinoamericana; o Khadria (200I), en el colectivo de profesionales indios especializados en tecnologías de la información.

Además, recientemente, algunos estudios cualitativos han querido subrayar aspectos que habían pasado inadvertidos en la literatura; por ejemplo, las razones y los factores que influyen en la emigración de este colectivo de alta cualificación, las motivaciones para escoger un país, las experiencias personales y las valoraciones sobre la cultura laboral y social del lugar de destino o las relaciones con el país de origen (por ejemplo, Hardill y MacDonald, 2000; Meijering y Van Hoven, 2003, Voigt-Graf, 2003, Ferro, 2004). En efecto, las decisiones para emigrar y las trayectorias laborales antes y después del proceso migratorio dependen y varían de forma notable en función de las características formativas de los inmigrantes, sus circunstancias personales, así como a partir de las percepciones y opiniones de los países y mercados laborales tanto de origen como de destino (Nagel, 2005), aunque las personas cualificadas eventualmente tendrían menos costos y más incentivos que los otros trabajadores a la hora de emprender una migración (Kennan y Walker, 2013).

\section{Metodología}

Este artículo se basa en 62 entrevistas semiestructuradas a inmigrantes cualificados en México, procedentes de España e Italia, que eran trabajadores de empresas en ese momento, realizadas en el marco de un proyecto general sobre inmigración cualificada en México, para el que se efectuaron 129 entrevistas semiestructuradas con españoles e italianos que contaran al menos con formación universitaria, resi- 
dentes en cuatro ciudades mexicanas. De estas, se llevaron a cabo 4I en la Ciudad de México, 3I en Guadalajara, 3I en Monterrey y 26 en Puebla entre octubre 2014 y septiembre 2015. Aunque la investigación no intentaba lograr una muestra representativa, se hicieron esfuerzos por recabar información de diversos tipos de inmigrantes: gerentes y técnicos de empresas transnacionales, académicos, empresarios y profesionales independientes (véase cuadro I). No fue posible un número igual por nacionalidad (españoles/italianos), ya que los nacidos en España superan a los italianos en una proporción 4:I en México, según los datos del Censo de Población y Vivienda mexicano del 2010 (INEGI, 20I6).

Debido a la falta de estadísticas oficiales confiables, se utilizó una técnica de muestreo de bola de nieve. Se informó a los participantes que las entrevistas serían tratadas en forma confidencial y se utilizarían pseudónimos en las publicaciones académicas resultantes de la investigación. La mayoría se realizaron en los puestos de trabajo, y algunas en los hogares de los entrevistados o en lugares públicos de su elección, como cafeterías. Las entrevistas, que duraron en promedio una hora, fueron transcritas totalmente. Se estructuraron a partir de tres ejes temáticos: trabajo y mundo laboral, integración social y cuestiones geográficas. En las respuestas, fue posible conocer las razones de migración a México, las intenciones de la estancia, comentarios sobre el mercado de trabajo de México (por ejemplo, puntos de vista sobre compañeros, profesionalismo, responsabilidad y discriminación en el trabajo), las experiencias cotidianas en las cuatro ciudades de estudio (nivel de vida, espacios cotidianos, imágenes del país y de la ciudad antes y después de la llegada a México), así como los vínculos con el país de origen. Los datos se analizaron con un método de análisis de contenido utilizando el software MAXQDA. Este proceso incluyó la codificación abierta, mediante la creación de categorías.

El estudio se centra en el personal de gestión y técnico de las empresas que constituyen prácticamente la mitad de la muestra no representativa (62 de I29; o 48.I \%; cuadro I). Entre estos profesionales, 20 han realizado su migración dentro de los mercados internos de las corporaciones transnacionales. Esa modalidad se ha definido como una transferencia temporal dentro de la empresa de, en principio, menos de tres años, que implica movilidad laboral ascendente. A estos profesionales, la literatura los ha denominado "expatriados" (Beaverstock, 2002; Millar y Salt, 2008). Los 42 entrevistados restantes han conseguido su empleo actual a partir de otros canales, ya sean contactos personales, profesionales o redes como LinkedIn, y se han podido integrar en empresas mexicanas o extranjeras, pero siempre con condiciones contractuales mexicanas. A pesar de que las entrevistas abordaban aspectos relativos a la inserción social o la vida diaria de estos colectivos en las cuatro 
ciudades de estudio, aquí nos centraremos específicamente en los aspectos laborales, tanto en cuestiones concernientes a su incorporación como a la movilidad dentro del mercado laboral mexicano. Por último, con la intención de completar algunos de los argumentos y debido a que el artículo supone un enfoque de trayectorias laborales, se ha usado información de algunas personas que fueron expatriados y que, en el momento de la entrevista, eran empresarios o trabajadores por cuenta propia.

\section{Cuadro I}

Inmigrantes españoles e italianos entrevistados, por sexo, edad, año de llegada y perfil profesional

\begin{tabular}{|c|c|c|c|c|c|}
\hline & & $\begin{array}{l}\text { Total } \\
\text { entrevistados }\end{array}$ & $\%$ & $\begin{array}{c}\text { Trabajadores } \\
\text { empresas }\end{array}$ & $\%$ \\
\hline \multirow{2}{*}{ Sexo } & Mujeres & 48 & 37.2 & 23 & $37+1$ \\
\hline & Hombres & $8 \mathrm{I}$ & 62.8 & 39 & 62.9 \\
\hline \multirow{3}{*}{ Edad } & 30 años y menos & 26 & 20.2 & II & 17.7 \\
\hline & 3I-49 años & 89 & 69.0 & 47 & 75.8 \\
\hline & 50 años y más & 14 & 10.9 & 4 & 6.5 \\
\hline \multirow{2}{*}{$\begin{array}{l}\text { Año } \\
\text { llegada }\end{array}$} & Antes 2008 & 37 & 28.7 & 16 & 25.8 \\
\hline & $2008-2015$ & 92 & $7 \mathrm{I}+3$ & 46 & 74.2 \\
\hline \multirow{5}{*}{$\begin{array}{l}\text { Perfil } \\
\text { profesional }\end{array}$} & $\begin{array}{r}\text { Personal de gestión } \\
\text { y técnico de las empresas } \\
\text { expatriados }\end{array}$ & 20 & 15.5 & & \\
\hline & $\begin{array}{l}\text { Trabajadores de las } \\
\text { empresas no expatriados }\end{array}$ & 42 & 32.6 & & \\
\hline & Académicos y profesores & 29 & 22.5 & & \\
\hline & $\begin{array}{r}\text { Empresarios y personal } \\
\text { por cuenta propia }\end{array}$ & 34 & 26.4 & & \\
\hline & Otros & 4 & $3+\mathrm{I}$ & & \\
\hline $\begin{array}{r}\text { TOTAL } \\
(\mathrm{n})\end{array}$ & & 129 & 100.0 & 62 & 100.0 \\
\hline
\end{tabular}

Fuente: Trabajo de campo (octubre 2014-septiembre 2015) 


\section{El papel de México como destino: temporalidad versus permanencia}

Los modelos explicativos centro-periferia de los años ochenta, en la línea de los primeros estudios que se realizaron sobre movilidad y migración del personal cualificado de las empresas, se han visto superados por el proceso de globalización actual que impone explicaciones más complejas en un mundo más interconectado. Esos modelos son de poca relevancia en el mundo contemporáneo actual, dado el papel que adquieren los nuevos países industrializados y, en el caso que nos ocupa, una economía emergente como México, que en este sentido se ha caracterizado por una relativa estabilidad política y económica en el contexto iberoamericano, y ha hecho al país atractivo para la inversión extranjera. La literatura, de hecho, se ha enfocado de forma frecuente en el análisis de los patrones de movilidad hacia las nuevas economías emergentes, aunque el énfasis siempre se ha puesto en los desplazamientos de los expatriados y los viajes de negocios, y no en la migración permanente (por ejemplo, Beaverstock, 2002; Millar y Salt, 2008; Faulconbridge et al., 2009). En el caso de nuestros entrevistados, México es mencionado de forma recurrente en las narrativas de los entrevistados como economía emergente y por sus posibilidades laborales. Con alguna excepción, la opinión dominante coincide en las amplias oportunidades de empleo, la facilidad para progresar y las buenas perspectivas económicas del país. A modo de ejemplo, el siguiente entrevistado, expatriado de una transnacional de construcción española, ilustra de forma muy gráfica por qué decidió regresar a México después de una primera etapa en la que se desplazó al país para un proyecto concreto.

Es una empresa de construcción. (...) En 2009 surgió un proyecto muy interesante aquí en México que era de un hospital (...) una asociación público-privada, en la que nosotros hicimos la inversión del hospital, el diseño de la construcción y, posteriormente, la operación del hospital. (...) Me vine con ese proyecto, estuve en la fase de diseño, luego en la de construcción. (...) Después volví a España en 2012 por ocho meses, estuve haciendo unos proyectos, pero no terminaron de arrancar. (...) Me propusieron regresarme y acepté el traslado y, desde entonces, llevo aquí y espero que por mucho tiempo. Decidí volver a México porque las cosas en España no estaban muy bien (Pedro, 34 años, ciudad mediana de Ciudad Real, E, expatriado, directivo, cuatro años en la Ciudad de México). 
Este mismo entrevistado explica posteriormente qué entiende por "no estaban bien" y se refiere no tanto a que no hubiera empleo (en el caso de los ingenieros, como menciona, el desempleo no es tan elevado), sino al hecho de que se hubieran devaluado los salarios y las condiciones laborales en general ("el problema son los sueldos, los han tirado al suelo, con lo cual un puesto en el que antes cobrabas diez, ahora te están ofreciendo cinco. Es el problema que mis compañeros se están encontrando en España"). De esta forma, Pedro se ve a futuro viviendo en México, hasta el punto que no le importaría eventualmente dejar la transnacional en la que está trabajando ("Si me surge una oportunidad en otra empresa, aunque no sea española, sí, me quedare”"), porque "las oportunidades laborales en México son buenas y creo que se dan oportunidades aquí que en España no hay".

No es un caso aislado. Víctor, con siete años en el país, llegó también como expatriado para organizar la sede mexicana de su empresa y ha superado, con mucho, los tres años inicialmente previstos por la empresa. Permanece en la misma compañía, especializada en coaching empresarial, como subdirector. Explica con las siguientes palabras su trayectoria laboral:

Entré en X (nombre de la empresa) de consultor de base en 1995. Y al cabo de un tiempo después de consultor, subí a gerente. (...) La empresa expandió sus operaciones en varios países y se necesitaba un director de operaciones que se ocupara de implantar los proyectos en diferentes países, de asesorar a los países en la implantación de los proyectos, hacer mejores prácticas y me toca a mí. En 2007 entró la crisis y me dijeron "necesitamos más valor añadido en los mercados, ¿te puedes ir un par de años a México, que es donde tenemos más potencial de expansión? Necesitamos a alguien que ayude a hacer crecer la oficina". Y me vine acá como director de operaciones. Y desde entonces estoy acá. (...) Me gusta mucho el trabajo. Estoy bien. Es una empresa que está creciendo. (...) En Madrid la empresa ya está muy aposentada y aquí es una empresa mucho más reciente. Es mucho más variada la labor, no hay rutina, te diviertes mucho. Aprendes mucho cada día. (...) Con todo lo que tiene de malo, México es un país que ofrece muchísimas cosas, y que me ofrece más cosas ahorita que España y hasta que Europa, por la economía, por un tema de agilidad mental, de que yo veo que las empresas aquí están dispuestas a hacer muchas más cosas que en España (Víctor, 48 años, Palma de Mallorca, E, expatriado, directivo, siete años en la Ciudad de México).

Víctor, después de siete años, mantiene gran parte de las condiciones laborales que tuvo como expatriado (sueldo, vacaciones, pago de casa). Su empresa valora 
el mercado mexicano en expansión, especialmente en tiempos de crisis en España. Además, añade otros aspectos interesantes que son claves para entender por qué quiere permanecer en el país, lo que él llama las "cosas" que ofrece México, que no se limitan a una mejor situación económica, sino a una cuestión de actitud: "las empresas aquí están dispuestas a hacer muchas más cosas que en España”, que están más abiertas a la innovación, lo cual es fundamental en el mundo del coaching empresarial al que está enfocada su compañía. De tal forma que "es más variada la labor, no hay rutina, te diviertes mucho".

Este es, de hecho, el caso de varios entrevistados que deciden permanecer, aunque tengan que renunciar a algunas de las prebendas que establecían sus contratos como expatriados. La renuncia, de todas maneras, es limitada, como de hecho fue el caso de Víctor, al poder negociar condiciones laborales, en general, ventajosas, comparadas con las de las personas cualificadas "locales". El siguiente entrevistado, Gonzalo, coincide con Víctor en las múltiples posibilidades laborales que ofrece el mercado laboral mexicano. En este caso, las cuestiones de motivación, innovación y aprendizaje son también básicas para entender por qué decide permanecer en México:

Estuve dos años en España, y un año y medio aquí en $\mathrm{X}$ (nombre de la empresa). Los resultados eran muy buenos, batiendo récords. Me cansé de hacer durante tres años y medio la misma actividad (adnetworking). Me plantearon llevarla al área de video, pero era la misma actividad, solo que cambiando el formato. Empecé a escuchar ofertas, y me contactó la actual empresa. (...) Me interesaba mucho lo que me ofrecía, porque era la parte de manejo de big data, lo que es diseño de targeting, impactar al usuario, analizando cuál ha sido el impacto, y tecnológicamente era mucho más avanzado, era más puntero (Gonzalo, 34 años, Vitoria, E, ex-expatriado, técnico responsable de área, tres años en la Ciudad de México).

Al optar por quedarse en México, este entrevistado renuncia a la transnacional que lo envió, tras valorar diversas opciones. Finalmente se decanta por la oferta laboral de otra compañía, especializada en el manejo de grandes bases de datos, más interesante desde su punto de vista profesional. En este caso, no sería tanto una mejora en las condiciones laborales (de hecho, pudo negociar el salario y las vacaciones, pero la nueva empresa no aceptó pagarle la vivienda), sino la posibilidad de poder desarrollar otros aspectos de su formación, que eventualmente pueden comportar una mejor y mayor especialización dentro de su campo.

En otros casos, se trata de empezar una nueva actividad económica, por ejemplo, emprender un negocio; una actividad que quizá sería mucho más compleja 
de realizar en España. Es el caso de Josep Lluís, de Barcelona, empresario de 42 años, casado y con un hijo, quien fue enviado a México como responsable de una filial española y actualmente tiene su propia empresa. Describe este proceso con las siguientes palabras:

Salió la oportunidad de comprar esta empresa. El paso a empresario fue fácil. Soy miembro del Club de Empresarios Catalanes en México. Había uno que se quería jubilar y regresar a Barcelona. Puso el negocio en venta, se dirigió a mí personalmente, me enseñó las cifras, me pidió un precio razonable, vi que había potencial, hipotequé todo y le compré el negocio (Josep Lluís, 42 años, Barcelona, E, ex-expatriado, empresario, siete años en Ciudad de México)

A partir de estos entrevistados, la idea que nos gustaría subrayar es que no todos los expatriados prefieren regresar al país de origen en cuanto acaban el tiempo establecido por la empresa, sino que algunos permanecen más allá del contrato con el que llegaron, otros optan por cambiar de empresa, y otros incluso deciden cambiar de actividad laboral. Como ya se ha visto anteriormente, esta evidencia no está en línea con la literatura sobre expatriados en países emergentes que subraya los patrones temporales de estos desplazamientos. México es, en definitiva, atractivo para gran parte de los entrevistados quienes, en muchos casos, deciden permanecer, lo cual contrasta con algunos proyectos migratorios pensados por ellos, en principio, solo como temporales. La falta de perspectivas laborales en los países de origen, particularmente en España, las facilidades para los negocios y, en general, la mayor estabilidad económica de México en el momento de las entrevistas hace viable la opción de quedarse, aunque sea perdiendo algunos de los beneficios establecidos en los contratos de los expatriados. Estos aspectos nos llevan, por otro lado, a rebatir los supuestos de los estudios sobre trabajadores de gestión y técnicos de las empresas. Estos estudios, que parten de visiones estáticas, transversales, de los colectivos de alta cualificación, presuponen que las corporaciones transnacionales son el lugar de destino preferido por este grupo. Es más, cuando se da una visión dinámica, la literatura se centra en la movilidad dentro de las empresas transnacionales, sin tener en cuenta las salidas o entradas fuera del mercado interno de estas empresas. Nuestro trabajo de campo plantea que la inserción dentro de las transnacionales y la condición de expatriado pueden ser un momento dentro de trayectorias laborales más complicadas. En esta complejidad, juega un papel relevante la situación económica tanto del país de origen como del de destino, y el papel que representa México en el concierto mundial. 


\section{El papel del Estado mexicano}

México es un país con una gran apertura a la economía internacional, en parte debido a los diversos tratados comerciales que ha firmado en las últimas décadas, pero no dispone de una política específica con respecto a la migración de alta cualificación para responder, en principio, a las demandas de la economía global. No es el caso de otros países que establecen programas orientados a atraer profesionales diversos (por ejemplo, el sistema de visados por puntos de Australia; Khoo, Graeme y McDonald, 20II). Es más, la necesidad de inversión directa extranjera ha impulsado a muchos de los considerados en vías de desarrollo a adoptar una posición menos restrictiva con respecto a la llegada de personal cualificado (por ejemplo, los casos de Indonesia, Malasia y China ilustrados por Koser y Salt, 1997). En la misma dirección, Pang (1993) afirma que países como Singapur, Malasia, Taiwán o Tailandia permiten, de forma relativamente fácil, la migración de profesionales para incorporarse en empresas extranjeras. Pero quizá el ejemplo más notorio de esta política sean algunas naciones árabes con ambiciosos planes de desarrollo que implican transferencia de tecnología y personal altamente especializado para la creación de empresas e instituciones, lo cual contrasta con sus políticas altamente restrictivas, en general, en materia de migraciones poco cualificadas. Incluso los países más pobres de África, al ver en la inversión de tecnología un primer paso para su desarrollo, han impulsado la contratación de trabajadores cualificados bajo modalidades de permisos de corta duración (Errichiello, 20I2).

Ciertamente, el papel del Estado es fundamental en la "bifurcación" de la "migración internacional global" actual que se daría entre la migración cualificada, tolerada e incluso incentivada por diferentes países, y la migración poco o sin cualificación que, en principio, se trataría de evitar (Castles y Miller, 2003). Como han puesto de manifiesto Kuptsch y Pang (2006), dado que el capital humano es una de las características que mejor definen la capacidad de adaptación de las sociedades, los países buscan mejorarlo no solo invirtiendo en educación, sino también atrayendo a migrantes. Se podría afirmar incluso que, para la mayoría de países, la única cara "aceptable" de la migración es la cualificada (Raghuram, 2013), aunque también es cierto que la mayoría de visados que se ofrecen a estos migrantes son temporales (Boyd, 2014).

Como se ha comentado anteriormente, México no dispone de un programa especial para atraer migrantes de alta cualificación. La nueva Ley de Migración 
mexicana ${ }^{3}$ se equipara con la de otros países, como los europeos, a la hora de solicitar un visado de trabajo antes de internarse en el país. Como ponen de manifiesto los entrevistados llegados antes de 20I2, previo a la promulgación de la ley, el paso de turista a inmigrante se realizaba estando en territorio mexicano. La necesidad de tramitar un visado de trabajo en el país de origen tampoco parece un problema para las grandes corporaciones, pero sí para las empresas de menor tamaño que se enfrentan a una ley relativamente nueva (el trabajo de campo se realizó entre octubre 2014 y septiembre 2015), y a una burocracia difícilmente inteligible para algunos entrevistados.

Las siguientes narraciones ilustran la variedad de situaciones a las que se enfrentan los inmigrantes a la hora de tramitar el permiso de trabajo en México. El primero es el ejemplo de un trabajador de una multinacional española que llegó como expatriado en 2007, antes del cambio en la ley. Posteriormente, una vez acabado el plazo de tres años marcado por la empresa, decidió permanecer en esta, como subdirector:

La renovación del permiso migratorio, lo hace la empresa por mí. (...) La persona que se ocupa de esto en la empresa me dice "Ve a las ocho de la mañana a las oficinas del Instituto de Migración". Esa persona está haciendo fila desde las seis y media, para hacer no sé cuántos trámites que prefiero no saber. Y yo llego a las ocho, y me pasa con un licenciado. Y ella pasa: "Buenos días, licenciado," "Buenos días, ¿̨por aquí de nuevo?", “Si”,"“Pásele,", "Traigo a otro español”. Firmo y ya está. Las cosas de documentación aquí son tremendas (Víctor, 48 años, Palma de Mallorca, E, expatriado, directivo, siete años en la Ciudad de México).

A partir de la entrada en vigor de la nueva ley, sin embargo, la situación es más complicada. La sensación que se tiene de las entrevistas no es tanto que el Instituto Nacional de Migración tenga la voluntad de negar el permiso de trabajo, sino que la burocracia es ineficiente y los plazos muy dilatados, hasta el punto en que algunos entrevistados permanecen de forma irregular en el país y renuevan su permiso como turista cada seis meses. Es su caso, Alberto explica que las empresas deben estar dadas de alta en un registro que les permita contratar extranjeros. Cuenta, con cierta ironía, que no es tan problemático como parece, porque aprovechan para hacer vacaciones $y$ así renovar su permiso de turista:

3 La Ley de Migración mexicana se aprobó en mayo de 20II, se empezó a aplicar en enero de 2012 y se reformó en abril de 2016 para contemplar el caso de los niños migrantes. 
Vinimos contratados con una empresa, nuestro contrato es español. Al principio, nos iban a hacer los papeles (a él y a su esposa), pero no es tan sencillo como parece. La empresa debe estar más de un año dada de alta en migración. De momento, cada I80 días tenemos que salir. Pero, por el trabajo, a veces tenemos que ir a Estados Unidos. Por vacaciones también salimos del país. Hasta ahora, no ha sido ningún problema (Alberto, 36 años, Barcelona, E, expatriado, técnico industrial, dos años en Puebla)

Un caso similar es el de Juan Antonio, quien también optó por entrar como turista. La empresa para la que trabajaba, como en el caso anterior, no estaba dada de alta en el registro de empleadores del Instituto Nacional de Migración y, por tanto, no podía contratar extranjeros. Este entrevistado además detalla los trámites que tuvo que realizar tanto en México como en España.

Tenía permiso migratorio de estudiante. Quisimos tramitar el cambio de residente sin actividad lucrativa a residente con actividad lucrativa. Tardaron en resolverme el trámite como diez meses. Salió negativo y me dijeron que tenía que abandonar el país en un mes. En paralelo, mi empresa tramitaba la constancia de empleador y el cambio de mi permiso de residente a residente con permiso de trabajo (...). Me lo denegaron porque mi institución, con la nueva ley, no cumplía los requisitos que pedían. Y me dijeron que tenía que salir del país. Salí, estuve un mes y medio en España, tramité el permiso de residencia con actividad lucrativa otra vez, pero en el Consulado de México en España, con contrato. Me dijeron que iban a tardar entre dos y diez días en responderme. Llevamos casi cuatro meses. Les he escrito como cuatro, cinco correos. He llamado como cuatro, cinco veces y ni me responden al teléfono. Entonces, tomamos la decisión de que tenía que volver. Entré como turista, I80 días, y hemos retomado el trámite del registro de empleador, que empezó en agosto del año pasado y finalmente se resolvió ayer. Esta parte ya quedó. Ahora falta mi permiso (Juan Antonio, 33 años, Sevilla, E, expatriado, directivo, un año y medio en Guadalajara)

Los casos anteriores son de trabajadores de empresas españolas de tamaño medio que han llegado a México en calidad de expatriados. A pesar de las buenas condiciones contractuales, dos de los tres entrevistados se han visto inmersos en una burocracia desconocida y, de acuerdo con sus narrativas, arbitraria. La situación es mucho más compleja, no obstante, para aquellos que migran fuera de los canales de las transnacionales. Las narrativas no recurren a la ironía o a una cierta resignación que se asocia con una cultura diferente, sino que, en estos casos, las descripciones 
de los trámites realizados se revisten con un cierto tono de impotencia y desengaño. Mariana, quien también entró como turista, con unos contactos que realizó vía Facebook (aunque anteriormente había visitado Chiapas en unas prácticas del máster de cooperación que cursó en su momento), explica que el proceso de obtención de empleo fue relativamente rápido, pero que lo realmente complicado fue conseguir el permiso de trabajo. La siguiente narración resume las vicisitudes que han experimentado varios entrevistados. En palabras de Mariana:

Entré como turista y al mes encontré trabajo, y ya empezaron a mover mis papeles. La empresa se inscribió en el Registro de Empleadores. La empresa presenta mi pasaporte, la oferta de empleo, y ahí ya me autorizan para hacer la entrevista. (...) Tendría que haber hecho la entrevista consular en España, antes de entrar. (...) Te obligan a salir. Afortunadamente se han puesto un poco más flexibles y te hacen la entrevista en cualquier país. (...) Pedí cita en el Consulado de México en Guatemala y fui, y me dijeron "hasta dentro de ocho días no te hacemos la entrevista". (...) Y las entrevistas son de dos minutos, de pie. (...) Es una entrevista bien intimidante, muy desagradable. Después de esa entrevista, te expiden una visa provisional de 30 días y, con esa, tramitas el permiso migratorio. (...) La empresa no me ha pagado todos estos meses que llevo trabajando y no tiene carácter retroactivo. Además, la mayoría de empresas que me encontré era así, no podían justificar el pago. (...) Su respuesta cínica es: "Tú nos haces el trabajo de voluntario estos meses y mientras te tramitamos el permiso de trabajo" (Mariana, 28 años, pueblo de Murcia, E, técnica de cooperación, seis meses en la Ciudad de México).

Los testimonios anteriores ponen en evidencia que la cuestión migratoria en México es compleja desde el cambio de la legislación. También revelan la vulnerabilidad legal a la que se ven sujetos algunos inmigrantes, particularmente los de menor edad y los que se incorporan a empresas mexicanas o extranjeras de tamaño medio o pequeño, como es el caso de Mariana y Alberto. Los aspectos de vulnerabilidad asociados a las cuestiones migratorias han sido puestos de relevancia por la literatura, pero centrados particularmente en la de los profesionales cualificados bajo esquemas de migración temporal, no tanto los aspectos relativos a la falta de documentación para residir o trabajar en el país de destino. En este sentido, Alarcón (2000) acunó el concepto high tech braceros, que hace referencia al programa de contratación temporal de mexicanos que implementaron los Estados Unidos en los sesenta para cubrir vacantes en la agricultura y que se relaciona con la precariedad de muchos profesionales en el país norteamericano, que son contratados bajo esquemas de 
visados temporales y sujetos a condiciones laborales poco favorables. Khoo, Graeme y McDonald (20II), a este respecto, apuntan que la política de visados temporales se convierte en un freno a la inmigración en Australia. Estos estudios, sin embargo, se centran en la inmigración en países considerados desarrollados y no se suponen para países con menos niveles de bienestar que, en principio, buscarían atraer personas de alta cualificación, como ocurre en el sureste asiático (Pang, 1993) o en los países del golfo pérsico (Errichiello, 20I2). En el caso de México, más bien, se pone de relevancia una falta de política migratoria específica con respecto a este colectivo que, eventualmente, podría ayudar en procesos de innovación o cambio empresarial en algunas ramas industriales o de servicios necesitadas de personal especializado.

\section{¿Movilidad laboral ascendente?: sueldo y condiciones laborales}

A pesar de las dificultades y trabas que supone lidiar con la aplicación de la política migratoria mexicana, los expatriados, en general, como vimos anteriormente, valoran muy positivamente su migración a México que, en general, se asocia con promoción laboral, mejores salarios y prestaciones diversas, como el pago de la vivienda, la escuela de los hijos o auto de empresa, como ha puesto de manifiesto la extensa bibliografía sobre expatriados (Koser y Salt, 1997; Iredale, 200I, Harvey y Beaverstock, 2016). Ciertamente, el sentimiento positivo ante el mercado laboral mexicano es la razón por la que muchos deciden quedarse en México, e incluso renunciar a su condición de expatriados, como es el caso de algunos entrevistados.

Estas opiniones positivas son mayoritaritas entre las personas de más edad y los que migraron antes de la crisis económica de 2008. Sin embargo, a partir de esa fecha, e incluso entre algunos expatriados, se observan matices en algunas narraciones, en el sentido que algunos de estos entrevistados han optado por migrar a México, dado que las condiciones laborales y la promoción laboral en el país de origen se estaban viendo mermadas por la crisis económica. La emigración sería un paso voluntario, pero, al mismo tiempo, necesario para progresar laboralmente en la transnacional. El no hacerlo podría provocar el estancamiento en el seno de la empresa en el país de origen, o incluso el despido. Por ejemplo, Pedro, ingeniero de una transnacional, está satisfecho con su decisión de migración a México y afirma, en su entrevista, que sus compañeros de la empresa en España están cobrando menos que en el pasado y algunos incluso están desempleados. 
En nuestro trabajo de campo, encontramos ejemplos de precarización laboral ligados a la falta de un permiso de trabajo, como vimos anteriormente, pero también salarios bajos, condiciones laborales no satisfactorias y contratación encubierta bajo esquemas de subcontratación. Un primer aspecto que llama la atención es, en algunos casos, el de los bajos salarios, especialmente porque, al menos desde una perspectiva neoclásica, el salario es el principal motivo de migración. Muchos valoran, más que el sueldo, la posibilidad de desarrollar sus carreras, ya que en su país de origen realizaban trabajos por debajo de su formación o estaban desempleados. De hecho, los sueldos de los entrevistados que no llegan a través de los mercados internos de las transnacionales varían mucho, siendo particularmente bajos para algunos profesionales jóvenes fuera de la Ciudad de México. Son los casos de Christian y Estrella, ambos residentes en Puebla, quienes mencionan que el salario es claramente insuficiente:

Pues solo con decirte que como mesero en España cobraba 17 ooo pesos (900 dólares aproximadamente) y aquí como periodista estoy cobrando 3 ooo. Imagínate cómo considero la situación acá. Aquí hay más oferta de lo mío, lógicamente, pero el salario es demasiado bajo (Christian, 28 años, Reus, Tarragona, E, periodista, 3 años en Puebla)

Veía a la gente que se iba fuera. Qué interesante, conoces cosas nuevas... pero ya venirte es otro rollo. Cuesta. Está muy lejos y con esa incertidumbre de que no sabes cuándo vas a poder volver porque aquí los sueldos tampoco son altos. Tienes que ahorrar mucho para poder viajar. Todo lo que juntas es para irte is días de vacaciones para ver a la familia (Estrella, 34 años, Badajoz, E, educadora ambiental, tres años en Puebla).

Encontramos también a aquellos que tienen un empleo, a menudo relacionado con su formación o/y aspiraciones profesionales, pero que, debido a los bajos salarios o costos de vida elevados, deciden emprender otras estrategias laborales para complementar sus ingresos. Por ejemplo, María (Rovereto, I, 28 años, dos años en Monterrey) se ocupa en dos empleos, uno relativo a su formación (publicista) y otro complementario (profesora de italiano en una escuela de idiomas). Otra opción es el empresariado en el sector informal, con la creación de pequeños negocios propios. De ello es ejemplo Andrea (Alicante, E, 37 años, siete años en Monterrey) que, a pesar de tener un cargo directivo en una importante universidad, se dedica además a elaborar jabón artesanal y a venderlo (por redes de amistades y en tiendas). En 
este caso, no sería tanto la necesidad de complementar su salario, sino la de iniciar una vocación en el mundo empresarial que le resulta atractiva.

Además del salario, las condiciones laborales, al ser comparadas con las españolas, se perciben como negativas, $y$ aquí se mencionan aspectos como las pocas vacaciones (según la Ley Federal del Trabajo, seis días laborales tras el primer año de trabajo, a los cuales se añaden dos más anualmente hasta el quinto año de trabajo), el acceso a la sanidad pública o el sistema de jubilación. Los comentarios con referencia a estos aspectos son muchos y variados. Laura quizá sea un caso extremo, porque, además de subrayar las malas condiciones laborales, opina que no le compensa trabajar en México. En este sentido, esta entrevistada comenta que, pese a los retrocesos sociales en España, las condiciones laborales no son comparables. Laura valora la oportunidad de poder ejercer de periodista en un diario local, pero tiene claro su regreso en un plazo razonable.

En cuanto a oportunidades, veo que hay más en México, por lo menos en el sector que yo me muevo, en comparación con España, hoy por hoy. En cuanto a profesionalismo y condiciones laborales es otra cosa. Las condiciones laborales mexicanas dejan bastante que desear, en cuanto a vacaciones, prestaciones laborales, seguro social, todo eso. Lo comparo con España y, a pesar de todo lo que hemos retrocedido, aún no se pueden comparar el mercado laboral mexicano y el español (Laura, 3I años, Madrid, E, periodista, tres años en la Ciudad de México).

Más allá de las condiciones laborales o del sueldo, quizá sorprenda que algunos entrevistados se enfrentan a contratos irregulares, relacionadas con procesos de subcontratación (outsourcing); es decir, laboran en empresas como prestadores de servicios. Estas prácticas no siempre son involuntarias, dado que algunos de los entrevistados prefieren un sueldo superior, aunque ello implique renunciar a algunos derechos laborales, como el seguro de salud. Estas prácticas, por otro lado, no son exclusivas de pequeñas empresas, que pueden experimentar contracciones en su volumen de negocios y se ven "obligadas" a usar este tipo de contratos, sino que se observan en grandes empresas, incluso en transnacionales, y, aunque esté fuera de los objetivos de este artículo, son frecuentes en la administración pública mexicana. El ejemplo siguiente ilustra el caso de Darío, un joven italiano que renunció a su empleo por acceder a un puesto en un banco español y que se encontró con unas condiciones laborales para él inaceptables: 
Estuve en (nombre de un banco español) tres semanas. (...) Me prometieron que me iban a contratar con todas las prestaciones, y después me llega un contrato de outsourcing $\sin$ las prestaciones de ley. Les dije, "La verdad, me regreso a mi casa". Me dijeron "Ya has dejado tu trabajo anterior, estás aquí, el sueldo a final de cuentas está bien”. (...) A mí no me dijeron que era outsourcing, sino, no hubiera aceptado desde el inicio. Hay muchas empresas así, les sale más económico. Te pagan lo mismo, pero se ahorran una cantidad (...) sin prestaciones, no tenía seguro, no tenía nada. (...) Tengo claro que el día que venga a devaluarme a nivel personal o a aceptar cosas de ese tipo, es el día que me regreso a mi casa. No estoy en otro país para estar peor de como estaría en mi casa. (...) No aceptaría trabajos así, sin vacaciones, sin... me voy a trabajar con mi familia, a Italia (Dario, 28 años, Bolzano/Bozen, Tirol del Sur, I, analista financiero, cinco años en la Ciudad de México).

"El día que venga a devaluarme a nivel personal o a aceptar cosas de ese tipo, es el día que me regreso a mi casa”. Estas palabras del último entrevistado reflejan, de forma fehaciente, que no todos los entrevistados confrontan sueldos, condiciones laborales o contractuales satisfactorias. Pero, además de estas situaciones "objetivas", que no siempre son tan positivas, los inmigrantes de alta cualificación pueden además enfrentarse a medios laborales muy diferentes, o incluso hostiles, a los de sus países de origen.

\section{Relaciones laborales $¥$ valores en conflicto}

Como se ha mencionado anteriormente, la literatura sobre migraciones cualificadas recientemente ha puesto de manifiesto aspectos que habían pasado inadvertidos, o se les había dado menor importancia, a la hora de decidir una migración, como son las motivaciones para escoger un país, las experiencias personales o las valoraciones sobre la cultura laboral y social del lugar de destino (por ejemplo, Meijering y Van Hoven, 2003, Voigt-Graf, 2003, Harvey y Beaverstock, 2016). También se ha apuntado las dificultades para acceder a la residencia permanente en el país de destino (Alarcón, 2000; Khoo, Graeme y McDonald, 20II), las no siempre óptimas condiciones de trabajo (Dean y Wilson, 2009) o los problemas de adaptación a las sociedades de destino de estos trabajadores cualificados (Tseng, 20II).

Las relaciones laborales y los conflictos que se pudieran derivar, por el contrario, no han sido ampliamente abordados en la literatura de migraciones, aunque sí se ha hecho desde la perspectiva de los estudios de gestión de empresa (Groysberg, Lee 
y Nanda, 2008; Dries, 2013). En estos estudios, el énfasis ha sido en los procesos de adaptación y ajuste de los expatriados de cara a optimizar sus estancias en los países de destino. Desde la geografía económica, por su parte, se ha hecho énfasis en la economía del conocimiento y en los flujos de información en el seno de las empresas y, desde otra perspectiva, entre ciudades globales, pero ignorando en gran medida los frenos a estos flujos por parte de las barreras culturales (por ejemplo, Faulconbridge et al., 2009; Hall y Appleyard, 201I).

En este sentido, en nuestras entrevistas encontramos de forma notable opiniones negativas de las relaciones laborales en el mercado de trabajo mexicano, particularmente entre los expatriados. Entre los inmigrantes independientes de las transnacionales, quizá debido al hecho de que puedan desarrollar sus carreras, se observa una mayor aceptación del mercado laboral local. Estas opiniones negativas son de tal intensidad que algún entrevistado se plantea dejar México porque no tolera la cultural laboral. Es el caso de Joan, de Tarragona, responsable de una transnacional belga y delegado comercial de España y Portugal en México. Su trabajo concreto es coordinar y supervisar la oficina en México de una empresa de aduanas encargada de buscar nuevos clientes, lo cual valora como especialmente conflictivo debido a una supuesta falta de profesionalidad de sus colegas mexicanos y de seriedad en los negocios. En sus palabras:

Mi situación laboral ha mejorado mucho desde el punto de vista salarial, pero, desde el punto de vista laboral, en general, ha empeorado mucho. Las condiciones de trabajo son muy precarias. No hay seriedad en los negocios. Realizar el trabajo para el que en teoría vine es una responsabilidad muy difícil, y más para un recién llegado como yo que no acaba de conocer muy bien la cultura laboral mexicana (Joan, 28 años, Tarragona, E, expatriado, delegado comercial en México de una transnacional, tres años en la Ciudad de México).

Este entrevistado se planteaba abandonar el país por cuestiones relacionadas con la cultura laboral mexicana e indica que las trayectorias laborales pueden variar a partir de las percepciones y opiniones de los países y mercados de trabajo tanto de origen como de destino, aunque, como mencionan Kennan y Walker (2013), las personas cualificadas, en principio, tendrían menos costos y más incentivos que el resto de trabajadores a la hora de incorporarse en el mercado laboral del país de destino. En este sentido, Oriol, de 46 años, quien decidió "probar" una experiencia internacional dentro del grupo francés de alimentación para el que trabaja, es también crítico con algunos aspectos de la cultura laboral mexicana, particularmente los relativos a la 
responsabilidad, el compromiso y la puntualidad, de tal forma que piensa que los objetivos de la empresa (y de los trabajadores) están muy orientados a corto plazo:

El ambiente de trabajo es muy diferente al de España. Es bueno. (...) La gente trabaja de forma diferente. El sentido de responsabilidad es muy bajo. El compromiso con la cultura de la empresa es muy bajo. Y la gente, en líneas generales, diría que está muy orientada a corto plazo. (...) Y la puntualidad es un concepto inexistente en el trabajo, con los amigos (Oriol, 46 años, expatriado, Barcelona, E, director de recursos humanos de una empresa transnacional francesa).

La falta de profesionalidad a la que se refiere Oriol es matizada por otros entrevistados, que opinan que el personal mexicano de alta cualificación que ha estudiado en universidades (privadas) del país son buenos profesionales y se comprometen con el trabajo de forma eficiente, mientras que los cargos intermedios y bajos, cuyos sueldos son sensiblemente inferiores, cuentan con un reducido nivel de compromiso con la empresa.

En todo caso, estas cuestiones no deben considerarse como aspectos menores del proceso migratorio y, en particular, de la inserción en el mercado laboral mexicano. La falta de entendimiento, la dificultad en las relaciones, la jerarquía, las jornadas excesivas o el tiempo de socialización fuera del trabajo son aspectos que no se han investigado ampliamente y se han considerado "menores" comparados con los relativos al sueldo o las prestaciones laborales. Sin embargo, son de vital importancia para entender el deseo de permanencia en una empresa e incluso en el país. En este sentido, el caso de Antonio, quien trabajó para una empresa mexicana como personal técnico, ilustra su confrontación con algunas normas laborales:

Era editor de inglés (en una agencia de noticias). Tenía mucha más libertad. (...) Soy un poco obsesivo cuando trabajo, lo hago muy rápido, y pues llegaba... me iba por las copichuelas, regresaba... como ya tenía todo, preparaba casi todo para el día siguiente, más o menos ya tenía mi agenda de tres días, salvo lo que sucediera, evidentemente. Y ya. Era muy bueno. (...) El conflicto vino porque querían más presencia, más calentar el puto asiento. (...) Incluso llegó una felicitación (...) porque ahora se entendían los pies de foto, los cables que mandaban. Y tuvieron el error de enseñarme la felicitación. Y cuando me empezaron a pedir "no, pues es que el horario", dije "a ver, o sea, llevo dos años trabajando así, me felicitan". Se empezó a distorsionar la relación, y fue cuando dije “ya, adiós" (...) Entonces dije "basta de este 
baño latinoamericano que no me deja nada más que enfados" (Antonio, Toledo, E, 39 años, editor y corrector de estilo, I3 años discontinuos en la Ciudad de México).

Este mismo entrevistado, que decidió regresar a Europa y posteriormente volvió a México, se incorporó en un segundo momento migratorio a una empresa de edición y corrección de textos. En el siguiente extracto menciona aspectos relativos a una supuesta discriminación laboral, derivada del hecho de ser extranjero. Antonio, al igual que otros entrevistados, apunta también cuestiones asociadas con la excesiva jerarquía y el poder:

Me dijeron que estaba aplicando un estilo muy formal, y una chica me decía que no, que eso no se decía así en México, que mi estilo de redacción era de otro país. $\mathrm{O}$ sea, me decía "no, no, no". Y fue un poco también de racismo. Ya van varias veces que me han hecho eso. (...) Es ese rollo de que tú como blanquito y como extranjero tienes muchas prebendas en México, muchas, muchas, muchas. Pero, en cuanto la gente tiene poder y nos les caes bien, pum. Tiran esa carta. A mí me la tiraron cuando utilizaba cierto giro, un cierto tono formal. Y me decían "no, es que eso no se dice asi'”. Y yo les decía "oye, a ver, sé cómo se habla aquí, ¿eh?” (...) Te hacen la vida imposible. Y es cuando dije "sabes qué, quédate tú con tu coto de poder. No te lo voy a quitar. Por eso has luchado tanto tiempo". Sobre todo es gente que lleva muchos años en una empresa (Antonio, Toledo, E, 39 años, editor y corrector de estilo, I3 años discontinuos en la Ciudad de México).

Estas críticas y opiniones negativas de las relaciones laborales podrían parecer menores, comparados con las ventajas que ostentan los expatriados en las transnacionales en México, aunque ya vimos que las situaciones son diversas y complejas. Es por ello que Gandini (2016) argumenta que a los inmigrantes de alta cualificación no se les permite ninguna acción reivindicativa de mejora laboral, por ser "privilegiados", en términos relativos, comparados con el resto de trabajadores. Esta autora opina que los inmigrantes cualificados están, en este sentido, privados de "derechos" y apunta una línea interesante de debate que, de nuevo, está poco presente en los estudios de migración cualificada.

\section{Conclusiones}


Este artículo ha querido poner en relevancia, a partir de un trabajo de campo amplio, aspectos que la literatura sobre migración cualificada ha ignorado o a los que, en su defecto, ha prestado poca atención. Dando voz a un colectivo de alta cualificación que labora en empresas privadas, se ha puesto de manifiesto que este es diverso, enfrenta variadas condiciones laborales y contractuales e incluso confronta, de diferente forma, las cuestiones migratorias, hasta el punto en que una parte de los entrevistados se encuentra en una situación migratoria irregular en México. Las diferencias estriban en, por un lado, en la edad del entrevistado y, relacionado con ello, el momento en que migró (antes o después de la crisis migratoria en 2008 / antes o después de la implementación de la nueva ley de migración en 20I2), así como con el canal a través del cual el migrante llega a México (fuera o dentro de las empresas trasnacionales). Estos tres elementos (edad, momento de la migración y calidad de expatriado) son decisivos para entender la inserción laboral y las trayectorias en México de los entrevistados y apuntan hacia una gran diversidad del colectivo de alta cualificación en México, tal y como también sugiere Nagel (2005). La idea que se desprende de lo anterior es que no existe, por tanto, un único modo de inserción laboral, homogéneo y no problemático, de la migración cualificada en México, sino que responde a diversos factores.

El aspecto en el que coinciden los entrevistados, al margen de las diferencias en cuanto a inserción laboral, es la valoración positiva del mercado de trabajo mexicano que se percibe como flexible, atractivo y con diversas opciones, de tal forma que incluso algunos entrevistados que llegaron a través de contratos temporales de corporaciones transnacionales deciden permanecer en el país. Estas opciones a futuro son valoradas particularmente por jóvenes que han migrado recientemente, debido, en parte, a las adversas condiciones laborales de las que proceden, en el sur de Europa. Significativamente, este colectivo es más receptivo a la cultura laboral mexicana que los transferidos dentro de las empresas trasnacionales, quienes, en principio, comparten valores, una ética profesional, con el personal local de esas mismas empresas. En todo caso, y aunque este aspecto no ha sido ampliamente discutido en el artículo, las entrevistas apuntan a que las experiencias laborales del colectivo de estudio en México están también influenciadas por el grado de integración social y cultural de estos inmigrantes en el país de destino, de tal forma que sus decisiones laborales, a menudo, dependen de factores exógenos a su experiencia en el lugar de trabajo.

Este artículo, en este sentido, pretende, a partir del análisis de estas experiencias, arrojar luz a la migración cualificada en un país que no ha sido considerado en la literatura de migraciones como atractivo para el personal de gestión o técnico de 
las empresas. Observando la realidad múltiple de este colectivo en México, se ha intentado complejizar el debate excesivamente enfocado en los países con mayor nivel de desarrollo y desde perspectivas y esquemas de interpretación rígidos. La migración a México parece responder a una doble dinámica de expulsión, motivada por la crisis económica, y de atracción, debido a las demandas específicas de algunos sectores de actividad y empresas en el país.

Retomando esta idea, en el artículo, además, se pone de manifiesto una tipología del personal cualificado de las empresas que superaría la división entre expatriados y profesionales "independientes". Esta tipología estaría relacionada con las trayectorias laborales previas a México y con las razones para migrar. Por un lado, se encuentran aquellos profesionales a los que podríamos calificar de "pioneros", cuyo trabajo consiste en abrir nuevos nichos de mercado o filiales, respondiendo en gran parte a los dictámenes de los centros operativos de las empresas. En este caso, sería el factor de atracción el que dominaría a la hora de decidir el proceso migratorio. Por el otro, se encuentran aquellos para los que la migración a México supone una oportunidad para desarrollarse profesionalmente aprovechando espacios laborales no satisfechos en sus países de origen. Aquí encontraríamos tanto factores de atracción como de expulsión a la hora de entender las decisiones migratorias. A diferencia de los otros dos casos, habría un último colectivo que migra a México por razones personales y que supedita sus decisiones laborales a esos motivos. Aunque el énfasis haya sido laboral en este artículo, es evidente que algunos de los incentivos para migrar o permanecer en México están relacionados con razones personales, como puede ser la pareja o los hijos (Ortiz-Guitart, en este mismo número).

\section{Bibliografía}

Ackers, Louise (2005), "Moving people and knowledge: Scientific mobility in the European Union", International Migration, 43(5), pp. 99-I3I. DoI: IO.IIII/j.I468-2435.2005.00343.x.

Alarcón, Rafael (2000),"Skilled immigrants and cerebreros: Foreign-born engineers and scientists in the high-technology industry of Silicon Valley", en Nancy Foner, Rubén G. Rumbaut y Steven Gold (eds), Immigration research for a new century, Nueva York, Russell Sage, pp. 30I-32I.

Angel-Urdinola, Diego F., Taizo Takeno y Quentin Wodon (2008), "Student migration to the United States and brain circulation: issues, empiral results, and programmes in Latin America", en Andrés Solimano (ed.), 
The international mobility of talent: Types, causes, and development impact, Oxford, Oxford University Press, pp. 145-167.

Appleyard, Reginald (1995), "Emigration dynamics in developing countries", International Migration, 33(3/4), pp. 293-314. DOI: IO.III/j.I4682435.1995.tbooo31.x.

Beaverstock, Jonathan V.(199I),"Skilled international migration: An analysis of the geography of international secondments within large accountancy firms", Environment and Planning A, 23(8), pp. II33-II46. DoI: I0.1068/ a231133.

Beaverstock, Jonathan V. (1996),"Subcontracting the accountant!: Professional labour markets, migration and organizational networks in the global accountancy industry", Environment and Planning A, 28(2), pp+303-326. DOI: I0.1068/a280303.

Beaverstock, Jonathan V. (2002), "Transnational elites in global cities: British expatriates in Singapore's financial district", Geoforum, 33(4), pp. 525538. DOI: 10.1016/Sool6-7185(02)00036-2.

Beaverstock, Jonathan V., Ben Derudder, James Faulconbridge y Frank Witlox (2009), Business travel in the global economy, Londres, Ashgate.

Bhagwati, Jagdish y Koichi Hamada (1974), "The brain drain, international integration of markets for professionals and unemployment: A theoretical analysis", Journal of Development Economics, I(I), pp. 19-42.

Bhagwati, Jagdish y Gordon Hanson (2009), Skilled immigration today: Prospects, problems, and policies, Oxford, Oxford University Press.

Boyd, Monica (200I), "Asian immigrant engineers in Canada", en Wayne Cornelius, Thomas J. Espenshade e Idean Salehyan (eds.), The international migration of the highly skilled: Demand, supply, and development consequences in sending and receiving countries, La Jolla, San Diego, Center for Comparative Immigration Studies, University of California, pp. 85-II2.

Boyd, Monica (2014),"Recruiting high skill labour in North America: Policies, outcomes and futures", International Migration, 52(3), pp. 41-54. DoI: IO.IIII/imig.I2139.

Castles, Stephen y Mark J. Miller (2003), The age of migration, Londres, Macmillan.

Chiswick, Barry R. (20II), High-skilled immigration in a global labor market, Washington DC, The American Enterprise Institute for Public Policy Research. 
Dean, Jennifer Asanin y Kathi Wilson (2009), "Education? It is irrelevant to my job now. It makes me very depressed...' Exploring the health impacts of under/unemployment among highly skilled recent immigrants in Canada", Ethnicity \& Health, I4(2), pp. I85-204. DoI: IO.1080/13557850802227049.

Docquier, Frédéric y Hillel Rapoport (20II), Globalization, brain drain and development, Lovaina, Institut de Recherches Economiques et Sociales de la Université Catholique de Louvain. <http://www.biu.ac.il/soc/ec/ wp/20II-I8.pdf> (consulta: $16 / \mathrm{II} / 2016$ ).

Dries, Nicky (2013), "The psychology of talent management: A review and research agenda", Human Resource Management Review, 23(4), pp. 272285. DOI: IO.IOI6/j.hrmr.2013.05.00I.

Dumont, Jean Christophe, Gilles Spielvogel y Sarah Widmaier (2010), International migrants in developed, emerging and developing countries: An extended profile, París, oECD Social, Employment and Migration Working Papers No.II4. <http://www.oecd.org/els/mig/46535333.pdf> (consulta: 15/07/2017).

Eich-Krohm, Astrid (2013),"Twenty-first century trends in highly skilled migration", en Steven J. Gold y Stephanie J. Nawyn (eds.), The Routledge International Handbook of Migration Studies, Londres, Routledge, pp.153-165.

Errichiello, Gennaro (2012), "Foreign workforce in the Arab Gulf States (19301950): Migration patterns and nationality clause", International Migration Review, 46(2), pp. 389-4I3. DoI* IO.III/j.I747-7379.20I2.0089I.X.

Faulconbridge, James, Jonathan V. Beaverstock, Ben Derudder y Frank Witlox (2009), "Corporate ecologies of business travel: Working towards a research agenda", European Urban and Regional Studies, I6(3), pp. 295308. DOI* I0.1177/0969776409104694.

Ferro, Anna (2004), "Romanians abroad: A snapshot of highly skilled migration", Higher Education in Europe, 29(3), pp. 381-39I. DoI: IO.1080/0379772042000331660.

Findlay, Allan M. (1989), "Skilled international migration: A research agenda", Area, 2I(I), pp. 3-II.

Findlay, Allan M., F.L.N Li, A.J. Jowett y Ronald Skeldon (1996), "Skilled international migration and the global city: a study of expatriates in Hong Kong", Transactions of the Institute of British Geographers, 2I(I), pp. 49-6I. DOI: $10.2307 / 622923$. 
Fratesi, Ugo (20I4), "Editorial. The mobility of high-skilled workers: Causes and consequences", Regional Studies, 48(I0), pp. 1587-1591. Dor: I0.1080/00343404.20I4.955689.

Fröbel, Friedrich, Jurgen Henricks y Otto Kreye (1980), The New International Division of Labour, Cambridge, Cambridge University Press.

Gandini, Luciana (20I6), "Migración calificada, desarrollo... y derechos: ¿la incógnita de la ecuación?", Ponencia presentada en el Congreso Internacional de Geografía Humana 2016. Espacios, lugares y territorios: Miradas latinoamericanas, Ciudad de México, Universidad Autónoma Metropolitana-Iztapalapa, IO-II de noviembre.

Giannetti, Mariassunta, Guanmin Liao y Xiaoyun Yu (2012), The brain gain of corporate boards: A natural experiment from China, Londres/Ontario, Centre for Economic Policy, Western University. <http://www.ivey. uwo.ca/cmsmedia/I6379I/gly_the_brain_gain_of_corporate_boards_ april_2I_20I2.pdf> (consulta: 07/OI/20I7).

Groysberg, Boris, Linda E. Lee y Ashish Nanda (2008),"Can they take it with them?: The portability of star knowledge workers' performance", Management Science, 54(7), pp. 1213-1230. DoI: 10.1287/mnsc.1070.0809.

Hall, Sarah y Lindsay Appleyard (20II),"Trans-local academic credentials and the (re)production of financial elites", Globalisation, Societies and Education, 9(2), pp. 247-264. DoI* I0.1080/14767724.2011.577177.

Hardill, Irene y Sandra MacDonald (2000), "Skilled international migration: The experience of nurses in the UK", Regional Studies, 34(7), pp. 68I692. DOI: 10.1080/00343400050178465.

Harvey, William S. y Jonathan V. Beaverstock (2016), “Diverging experiences of work and social networks abroad: Highly-skilled British migrants in Singapore, Vancouver and Boston", en Micheline van Riemsdijk y Qingfang Wang (eds), Rethinking international skilled migration: A place-based and spatial perspect, Londres, Routledge, pp. 268-292.

INE (2017), Encuesta de Población Activa. Trimestre 4/2016, Madrid, Instituto Nacional de Estadística, <http://www.ine.es/dyngs/INEbase/es/ operacion.htm?c=Estadistica_C\&cid $=1254736176918 \&$ menu $=$ resultados\&idp=I254735976595\#> (consulta: 05/05/2017).

INE (20I6), Estadística del Padrón de Españoles Residentes en el Extranjero (PERE), Madrid, Instituto Nacional de Estadística. <http://www.ine.es/jaxi/ menu.do? $\mathrm{L}=0$ \&type $=$ pcaxis $\&$ path $=\% 2 \mathrm{Ft} 20 \% 2 \mathrm{Fp} 8500 \mathrm{I} \&$ file $=$ ine base > (consulta: $\mathrm{II} / \mathrm{II} / 20 \mathrm{I} 6)$. 
inegi (2016), Censo de Población y Vivienda 2010, Ciudad de México, Instituto Nacional de Estadística y Geografía. <htttp://www.inegi.gob.mx> (consulta: 15/10/2016).

Iredale, Robyn (200I),"The migration of professionals: Theories and typologies", International Migration, 39(5), pp. 7-26. DoI: I0.1111/1468-2435.00169. Kennan, John y James R. Walker (2013), "Modeling individual migration decisions", en Amelie F. Constant y Klaus F. Zimmermann (eds.), International Handbook on the Economics of Migration, Chelthenham, Edward Elgar, pp. 39-54.

Khadria, Binod (200I), "Shifting paradigms of globalization: The twenty-first century transition towards generics in skilled migration from India", International Migration, 39(5), pp. 45-7I. DOI: I0.IIII/I468-2435.00I7I.

Khadria, Binod (2009),"Adversary analysis and the quest for global development: Optimizing the dynamic conflict of interest in transnational migration", Social Analysis: The International Journal of Social and Cultural Practice, 53(3), pp. I06-I22. DOI: 10.3167/sa.2009.530306.

Khoo, Siew-Ean, Hugo Graeme y Peter McDonald (20II), "Skilled migration from Europe to Australia”, Population, Space and Place, I7 (5), pp. $550-$ 566. DOI: 10.1002/psp.65I.

Koser, Khalid y John Salt (1997),"The geography of highly skilled international migration", International Journal of Population Geography, 3(4), pp. 285-303. DOI: IO.1002/(SICI)IO99-I220(I997I2)3:4<285::AID-IJP$\mathrm{G}_{72}>3 \cdot 0 . \mathrm{CO} ; 2-\mathrm{W}$.

Kuptsch, Christiane y Eng Fong Pang (2006), Competing for global talent, Ginebra, International Labour <http://www.ilo.org/wcmsp5/groups/ public/@dgreports/@dcomm/@publ/documents/publication/ wcms_publ_9290I47768_en.pdf> (consulta: 23/oI/2017).

Lozano Fernando y Luciana Gandini (20II),"Migración calificada y desarrollo humano en América Latina y el Caribe", Revista Mexicana de Sociología, 73(4), pp. 675-713.

Meier, Lars (2015), "Introduction: local lives, work and social identities of migrant professionals in the city", en Lars Meier (ed.), Migrant professionals in the city: Local encounters, identities and inequalities, Londres, Routledge, Pp. I-2O.

Meijering, Louise y Bettina van Hoven (2003),"Imagining difference: The experiences of 'transnational' Indian IT professionals in Germany", Area, 35(2), pp. I74-I82. DOI: IO.IIII/I475-4762.00253. 
Mendoza, Cristóbal (1994), La mobilitat dels estrangers en les empreses transnacionals: Les empreses alemanyes de dos sectors econòmics a Catalunya, tesis de maestría, Dpto, de Geografía. Universidad Autónoma de Barcelona. <http://www.fbofill.cat/sites/default/files/Eorg2.pdf> (consulta: O2/02/2017).

Mendoza, Cristóbal y Anna Ortiz-Guitart (2006),"Hacer las Américas: Migrantes españoles de alta calificación en la Ciudad de México", Documents d’Anàlisi Geogràfica, vol. 47, pp. 93-II4.

Millar, Jane y John Salt (2008), "Portfolios of mobility: The movement of expertise in transnational corporations in two sectors-aerospace and extractive industries", Global Networks, 8(I), pp. 25-50. DoI* I0.IIII/j.I47I0374.2008.00184.X.

Nagel, Caroline R. (2005), 'Skilled migration in global cities from 'other' perspectives", Geoforum, 36(2), pp. 197-210. DoI: 10.1016/j.geoforum.2003.06.003.

Noceda, Miguel Ángel (2005), "De los abarrotes al éxito", El País, Suplemento Empresas, 23 de octubre, p. 8.

Ong, Aihwa (1999), Flexible citizenship: The cultural logics of transnationality, Durham, Duke University Press.

Palma Mora, Mónica (2006), De tierras extrañas: Un estudio sobre la inmigraciòn en México 1950-199o, Ciudad de México, Instituto Nacional de Migración/DGE Ediciones.

Pang, Eng Fong (1993), "Labour migration to the newly-industrialising economies of South Korea, Taiwan, Hong Kong and Singapore”, International Migration, 3I(2-3), pp. 300-313. DOI* I0.11II/j.I468-2435.1993.tboo705.x.

Peixoto, João (200I), “The international mobility of highly skilled workers in transnational corporations: The macro and micro factors of the organizational migration of cadres", International Migration Review, 35(4), pp. I030-I053. DOI* I0.IIII/j.I747-7379.200I.tboo05I.x.

Pellegrino, Adela (200I), "Trends in Latin America skilled migration: 'Brain drain' or 'brain exchange'?", International Migration, 39(5), pp. III- I32. DOIः IO.IIII/I468-2435.00I74.

Portes, Alejandro (1976), “Determinants of the brain drain”, International Migration Review, Io(4), pp. 489-508, DoI* 10.2307/254508I.

Raghuram, Parvati (2013), "Theorising the spaces of student migration", Population, Space and Place, 19(2), pp. I38-154. DoI: 10.1002/psp.I747.

Relea, Francesc (2005), “Una pica al sur del río Bravo”, El País, Suplemento Empresas, 23 de octubre, pp. 5-6. 
Rodríguez Chávez, Ernesto y Salvado Cobo (2012), Extranjeros residentes en México: Una aproximación cuantitativa con base a los registros administrativos del INM, Ciudad de México, Centro de Estudios Migratorios-Instituto Nacional de Migración. <http://www.politicamigratoria.gob. $\mathrm{mx} /$ work/models/sEGOB/CEM/PDF/Estadisticas/Poblacion_Extranjera/ExtranjerosResMex.pdf> (consulta: 10/02/2017):

Salt, John (1992),"Migration processes among the highly skilled in Europe", International Migration Review, 26(2), pp. 484-505. DOI: 10.2307/2547068.

Smith, Michael Peter y Adrian Favell (2006), The buman face of global capital: International highly skilled migration in Europe, North America and the Asia-Pacific, New Brunwick, NJ, Transaction Publishers.

Solimano, Andrés (2008), The international mobility of talent: Types, causes, and development impact, Oxford, Oxford University Press.

Tseng, Yen-Fen (20II), "Shanghai Rush: Skilled migrants in a fantasy city", Journal of Ethnic and Migration Studies, 37(5), pp. 765-784. DoI: I0.1080/1369183X.2011.559717.

Voigt-Graf, Carmen (2003), "Fijian teachers on the move: causes, implications and policies", Asia Pacific Viewpoint, 44(2), pp. 163-175. DoI* 10.1111/14678373.00191.

Willis, Katie y Brenda S. Yeoh (2000), "Gender and transnational household strategies: Singaporean migration in China”, Regional Studies, 34(3), pp. 253-264. DOI: I0.1080/00343400050015096.

Resumen CURRICUlar

Cristóbal Mendoza es doctor (PhD) por la Universidad King's College de Londres. Cuenta con una maestría en Geografía por la Universidad Autónoma de Barcelona y con un posgrado en estudios de población por el Centro de Estudios Demográficos de la misma universidad. Desde septiembre 2004 es profesor investigador titular del Departamento de Sociología de la Universidad Autónoma Metropolitana-Iztapalapa, de la Ciudad de México, y, desde enero 2016 es coordinador de la Licenciatura en Geografía Humana de dicha universidad. Es miembro del Sistema Nacional de Investigadores (nivel II). Ha publicado en revistas de referencia internacional como Progress in Human Geography, International Migration, International Journal of Tourism Research, Latin American Research Review, Geoforum y Journal of Ethnic and Migration Studies. Recientemente ha coordinado La periferia metropolitana: Entre la ciudad prometida y un lugar para habitar la Ciudad de México (Gedisa, 2015, 
con Alicia Lindón). Sus líneas de investigación actuales se centran en la migración México-Estados Unidos, la migración cualificada y la geografía de las migraciones. Correo electrónico: cmp@xanum.uam.mx

Citar como: Mendoza, Cristóbal (2018), "Migración y movilidad de los trabajadores cualificados extranjeros de las empresas en México", Iztapalapa. Revista de Ciencias Sociales y Humanidades, núm. 84, año 39, enero-junio de 20I8, ISSN 2007-9176; pp. 15-47. Disponible en <http://revistaiztapalapa. izt.uam.mx/index.php/izt/issue/archive $>$. 